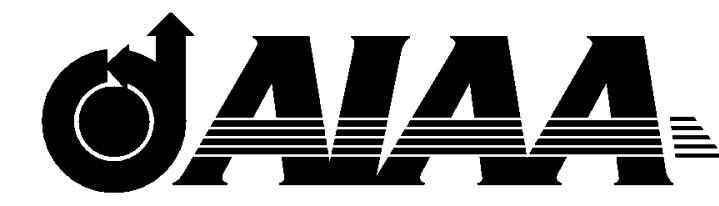

\title{
AIAA 2001-2825 Heat Transfer in Adhesively Bonded Honeycomb Core Panels
}

Kamran Daryabeigi

NASA Langley Reseacrh Center

Hampton, VA

35th AIAA Thermophysics Conference

$$
\begin{gathered}
\text { 11-14 June } 2001 \\
\text { Anaheim, CA }
\end{gathered}
$$

For permission to copy or to republish, contact the copyright owner named on the first page. For AIAA-held copyright, write to AIAA Permissions Department, 1801 Alexander Bell Drive, Suite 500, Reston, VA, 20191-4344. 
AIAA 2001-2825

\title{
HEAT TRANSFER IN ADHESIVELY BONDED HONEYCOMB CORE PANELS
}

\author{
Kamran Daryabeigi* \\ NASA Langley Research Center \\ Hampton, Virginia
}

\begin{abstract}
$\underline{\text { Abstract }}$
The Swann and Pittman semi-empirical relationship ${ }^{1}$ has been used as a standard in aerospace industry to predict the effective thermal conductivity of honeycomb core panels. Recent measurements of the effective thermal conductivity of an adhesively bonded titanium honeycomb core panel using three different techniques, two steady-state and one transient radiant step heating method, at four laboratories varied significantly from each other and from the Swann and Pittman predictions. Average differences between the measurements and the predictions varied between 17 and 61 percent in the temperature range of 300 to $500 \mathrm{~K}$. In order to determine the correct values of the effective thermal conductivity and determine which set of the measurements or predictions were most accurate, the combined radiation and conduction heat transfer in the honeycomb core panel was modeled using a finite volume numerical formulation. The transient radiant step heating measurements provided the best agreement with the numerical results. It was found that a modification of the Swann and Pittman semi-empirical relationship which incorporated the facesheets and adhesive layers in the thermal model provided satisfactory results. Finally, a parametric study was conducted to investigate the influence of adhesive thickness and thermal conductivity on the overall heat transfer through the panel.
\end{abstract}

Nomenclature
$q^{\prime \prime}$ heat flux
$\mathrm{T}$ temperature
$\varepsilon \quad$ Emissivity

$\begin{array}{ll}\text { Subscripts: } \\ \text { ad } & \text { adhesive } \\ \text { f } & \text { foil } \\ \text { e } & \text { effective } \\ \text { fs } & \text { facesheet } \\ \text { g } & \text { gas } \\ \text { r } & \text { radiant }\end{array}$

A cross sectional area

$\mathrm{F}$ radiation shape factor

$\mathrm{k}$ thermal conductivity

L height (thickness)

$\mathrm{L}^{\prime}$ honeycomb core height

$r$ radial coordinate

$\mathrm{z}$ axial coordinate

$\delta$ Kronecker delta

$\lambda$ height to diameter ratio for honeycomb cell

$\sigma$ Stefan-Boltzmann radiation constant

Acronyms

ASTM American Society of Testing and Materials

GHP Guarded Hot Plate

NIST National Institute of Standards and Technology

SRM Standard Reference Material

S\&P Swann and Pittman

Aerospace Engineer, Member AIAA

Copyright (C) 2001 by the American Institute of Aeronautics and Astronautics, Inc. No copyright is asserted in the United States under Title 17, U.S. Code. The U.S. Government has a royalty-free license to exercise all rights under the copyright claimed herein for Governmental Purposes. All other rights are reserved by the copyright owner. 


\section{Introduction}

An adhesively bonded titanium honeycomb core skin panel was considered for the wing structure of the High Speed Civil Transport not only for its structural performance, but also because of its low effective thermal conductivity in order to minimize heating of the fuel stored in the wings. Measurements of the effective thermal conductivity of typical honeycomb core panels using three different standard techniques at four different thermophysical property measurement laboratories in the temperature range of $300-500 \mathrm{~K}$ yielded results that were significantly different from each other and from the semi-empirical Swann and Pittman ${ }^{1}$ model for combined radiation and gas and solid conduction heat transfer in honeycomb core panels. The Swann and Pittman model has been used as the standard model for determining heat transfer through honeycomb core structures throughout the aerospace industry. The significant difference in the measured and predicted values of effective thermal conductivity and the wide variation among the measurements using various techniques required a more thorough investigation of heat transfer through this specific honeycomb core panel.

The purpose of the present investigation was to determine the effective thermal conductivity of honeycomb core panel. This was accomplished by a finite volume numerical solution to the combined radiation/conduction heat transfer for the specimen. The results were then compared with the Swann and Pittman predictions and the experimental results to determine which set was most accurate. Then, modifications to the Swann and Pittman model that incorporated the facesheets and adhesive layers in the thermal model were investigated and compared with the finite volume numerical results. Finally, a parametric study was conducted to investigate the influence of adhesive thickness and thermal conductivity on the overall heat transfer through the panel.

\section{Background}

Various researchers have investigated heat transfer in honeycomb core structures. Most of the work reported in the literature has been limited to panels with the honeycomb core brazed to the facesheets. None of the available literature has considered adhesively bonded honeycomb structures. Furthermore, the majority of the reported work has neglected either radiation or gas conduction heat transfer. Swann and Pittman used a finite difference model to study combined conduction and radiation in honeycomb structures and used their results to derive a semi- empirical relationship for the effective thermal conductivity as a function of geometric parameters and material properties. Stroud ${ }^{2}$ measured effective thermal conductivities of four honeycomb core panels over a temperature range of 670 to $1050 \mathrm{~K}$ and showed a root mean square deviation of $7 \%$ between his measured values and predictions using the Swann and Pittman semi-empirical relationship. Eftekhar, et al., 3 developed a simplified analytical solution for twodimensional conduction heat transfer in a rectangular enclosure, neglecting radiation heat transfer.

Fairbanks ${ }^{4}$ formulated effective thermal conductivity of square cells for heat flow lateral to the principal axes of the cells for honeycomb core mirrors in space-based applications. Jones ${ }^{5}$ modeled combined solid conduction and radiation heat transfer through evacuated honeycomb cored panels. Copenhaver, et al., ${ }^{6}$ used the finite element numerical technique to model combined conduction/radiation in honeycomb core panels and used parameter estimation techniques in conjunction with experimental heating data to estimate specific heat of the facesheets, emissivity in the core and the conduction area of the core.

Most of the reported work has concentrated on conduction and radiation as the prevalent modes of heat transfer and has neglected natural convection. Edwards, et al., ${ }^{7}$ studied natural convection in honeycomb structures and determined the critical Rayleigh number for the onset of natural convection in square cell honeycombs. The maximum calculated Rayleigh number for the titanium honeycomb core panel studied here was determined to be 7900 , which was lower than the critical Rayleigh number for this geometry, 61000, and therefore, natural convection was not considered as a mode of heat transfer in the present study.

\section{Honeycomb Core Panel Description}

The honeycomb core panel used in this study was made of titanium $3 \mathrm{Al}-2.5 \mathrm{~V}$ with a density of 94.5 $\mathrm{kg} / \mathrm{m}^{3}$. The core was $25.4 \mathrm{~mm}$ thick and consisted of $4.76 \mathrm{~mm}$ non-corrugated hexagonal cells with 0.035 $\mathrm{mm}$ foil thickness. The facesheets were made of titanium 6-22-22 and were $1.6 \mathrm{~mm}$ thick. The honeycomb core was attached to the facesheets using a modified epoxy adhesive film (FM5) supported by a polyester knit fabric. Two layers of the adhesive at $0.49 \mathrm{~kg} / \mathrm{m}^{2}$ were applied to each facesheet. The adhesive thickness was determined to be $0.94 \mathrm{~mm}$. 


\section{$\underline{\text { Swann and Pittman Model }}$}

Swann and Pittman developed a semi-empirical model for heat transfer through honeycomb sandwich panels. ${ }^{1}$ They assumed that the facesheets' thicknesses were very low to make the thermal contribution of the facesheets negligible, and thus simply modeled heat transfer through the honeycomb core structure. They considered solid conduction through honeycomb cell walls, gas conduction in the honeycomb cells, and radiation heat transfer in the honeycomb cell enclosure. They developed an empirical relationship for modeling radiation in the honeycomb core enclosure, and used a parallel thermal network model for modeling solid and gas conduction through the honeycomb core. The effective thermal conductivity, $\mathrm{k}_{\mathrm{e}}$, is given by:

$$
\mathrm{k}_{\mathrm{e}}=\mathrm{k}_{\mathrm{f}} \frac{\Delta \mathrm{A}}{\mathrm{A}}+\mathrm{k}_{\mathrm{g}}\left(1-\frac{\Delta \mathrm{A}}{\mathrm{A}}\right)+\mathrm{k}_{r}
$$

where $\mathrm{k}_{\mathrm{f}}$ is the thermal conductivity of honeycomb core foil parent material, $\mathrm{k}_{\mathrm{g}}$ is the thermal conductivity of the gas contained in the panel, and $\triangle \mathrm{A} / \mathrm{A}$ is the ratio of the cross sectional areas of the solid core to the overall honeycomb cell. The radiation effective conductivity, $\mathrm{k}_{\mathrm{r}}$, is given by:

$$
\begin{gathered}
\mathbf{k}_{\mathrm{r}}=0.664(\lambda+0.3)^{-0.69} \varepsilon^{1.63(\lambda+1)^{-0.89}} \\
\mathrm{~L}^{\prime} \sigma\left(\mathrm{T}_{1}+\mathrm{T}_{2}\right)\left(\mathrm{T}_{1}^{2}+\mathrm{T}_{2}^{2}\right)
\end{gathered}
$$

where $\sigma$ is the Stefan-Boltzmann radiation constant, and $T_{1}$ and $T_{2}$ are the temperatures of the facesheets, $L^{\prime}$ is the honeycomb core height, $\lambda$ is the ratio of height to diameter for a cell in the honeycomb panel, and $\varepsilon$ is emissivity. It is assumed that the facesheets and honeycomb core have the same emissivity. The radiation effective conductivity function is an empirical relationship developed by Swann and Pittman using a trial and error process by comparing results with a finite difference model of the combined conduction/radiation heat transfer process in the honeycomb cell.

The ratio of the cross sectional areas of the solid cores to the overall honeycomb cell required for calculations in Eq. (1) was calculated based on the ratio of the mass density of the honeycomb core to the bulk material, and for the current honeycomb geometry this ratio was 0.0208 . For the Swann and Pittman semiempirical relationship and the finite volume numerical heat transfer model, the hexagonal honeycomb cells were modeled as circular cells. The equivalent diameter of the circular cell was obtained by equating the perimeters of the hexagonal and circular cross sections as suggested by Swann and Pittman. ${ }^{1}$ The equivalent diameter was therefore found to be 9.096 $\mathrm{mm}$. This would result in the height to diameter ratios, $\lambda$, of 2.79 when ignoring the adhesive layers, and 2.58 when including the adhesive layers.

\section{Experimental Measurements}

The effective thermal conductivity of the honeycomb core panel had been measured using three different techniques at four thermophysical property measurement laboratories. Two laboratories utilized the guarded hot plate technique, ${ }^{8}$ which is an absolute steady state technique. This technique is reported to have uncertainties of $\pm 5 \%$ when measuring thermal conductivity of high- density rigid specimen. ${ }^{8}$ One laboratory used the heat flow meter apparatus based on American Society of Testing and Materials (ASTM) Standard C518, ${ }^{9}$ which is a steady-state comparative technique, requiring specimens of known transmission properties to calibrate the heat flux transducers used in the apparatus. The measurement laboratory stated the general overall uncertainty of their measurement as $\pm 5 \%$. One laboratory used a transient radiant step heating technique. One face of the specimen is subjected to a step radiant heating, and temperatures are measured on both sides of the specimen. The thermal diffusivity of the specimen is determined by minimizing the sum of square of differences between measured and predicted temperatures using a one dimensional finite difference model of the heat conduction equation through the sample assuming the test specimen is a homogenous material. The thermal conductivity is then calculated from the thermal diffusivity by knowing or measuring the specimen specific heat. No measurement uncertainties were available for the data generated using this technique. All the measurements were performed on $203.2 \mathrm{~mm}$ diameter specimen, except for the radiant step heating technique which used a $203.2 \mathrm{~mm}$ diameter specimen for the room temperature measurement and a $50.8 \mathrm{~mm}$ diameter specimen for measurements above room temperature.

The variation of the measured thermal conductivity with average specimen temperature for the temperature range of 300 to $450 \mathrm{~K}$ using the measurements from the three different techniques at the four laboratories are shown in Figure 1. The prediction of the effective thermal conductivity from the semi-empirical Swann and Pittman ${ }^{1}$ model is also included in the figure. Error bars used for the steady-state techniques correspond to the stated $\pm 5 \%$ measurement uncertainty; no error estimates were available for the radiant step heating technique. The first observation is that the measurements using the three techniques were 
significantly different from each other. Even the measurements using the guarded hot plate technique, which is an absolute measurement technique and is the most frequently used method for thermal conductivity measurement, at the two different laboratories were significantly different from each other. The guarded hot plate data from the two laboratories agreed at room temperature, but diverged from each other as the specimen temperature increased. The heat flow meter data were lower than the guarded plate data, but did not exhibit the same trend as the other data. The thermal conductivity increased with increasing temperature up to $370 \mathrm{~K}$, and then asymptotically approached a constant value. The measurements at this laboratory used the National Institute of Standards and Technology (NIST) standard reference material (SRM) $1450 \mathrm{~b}$, a fibrous glass board, for calibrating the heat flux transducers. Since the standard reference material had a lower thermal conductivity than the honeycomb core panel, the results were obtained by extrapolating the heat flux transducers' calibration curves which may have resulted in higher uncertainties than the stated general uncertainty of $\pm 5 \%$, especially at higher temperatures. The radiant step heating technique produced the lowest measured thermal conductivities and was closest to the Swann and Pittman predictions.

The second observation is that the data for the four measurements were all significantly different from the Swann and Pittman predictions. The average percent difference over the entire temperature range, with the corresponding $95 \%$ confidence intervals, ${ }^{10}$ between the measurements and the Swann and Pittman predictions were $51.7 \pm 3.1,60.9 \pm 28.7,28.4 \pm 15.8$, and $17.4 \pm 28.4$ for the two guarded hot plate data, heat flow meter data, and the radiant step heating data, respectively. The data are also presented in Table 1.

\begin{tabular}{|l|c|}
\hline $\begin{array}{l}\text { measurement } \\
\text { technique }\end{array}$ & $\begin{array}{c}\text { average percent } \\
\text { difference with respect } \\
\text { to Swann \& Pittman }\end{array}$ \\
\hline Guarded hot Plate-1 & $51.7 \pm 3.1$ \\
\hline Guarded hot Plate-2 & $60.9 \pm 28.7$ \\
\hline heat flow meter & $28.4 \pm 15.8$ \\
\hline radiant step heating & $17.4 \pm 28.4$ \\
\hline
\end{tabular}

Table 1. Average percent difference of various experimental data with respect to Swann and Pittman model. $^{1}$

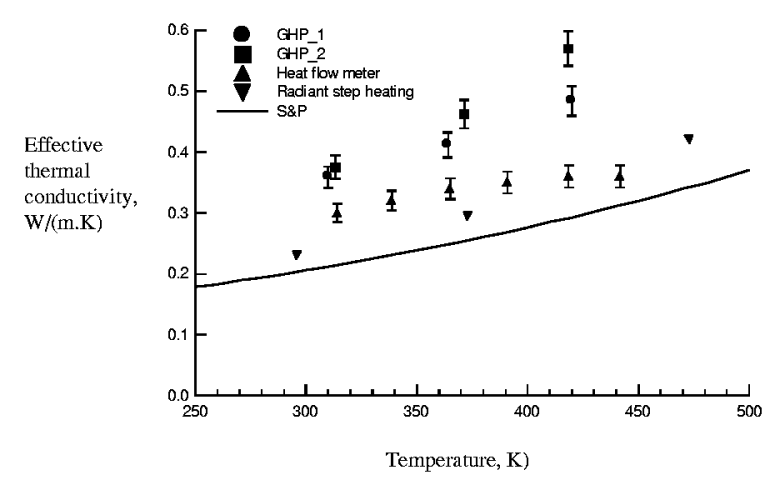

Figure 1. Comparison of the measured effective thermal conductivities of the adhesively bonded honeycomb core panel using three techniques at four laboratories with Swann and Pittman model. ${ }^{1}$

\section{Combined Conduction/Radiation Heat Transfer in Honeycomb Panel}

A steady state finite volume numerical method was used to solve the combined conduction/radiation heat transfer in the honeycomb core panel. The governing equations were applied to a volume representing one cell of the honeycomb core and the associated facesheets and adhesive layers. The hexagonal core of the honeycomb was approximated as having a circular cross section. Swann and Pittman had used the same approximation in their finite difference numerical solution of the problem. This approximation reduced the problem to an axisymmetric case. In the absence of natural convection, the governing partial differential equation for conduction heat transfer is:

$$
\frac{1}{\mathrm{r}} \frac{\partial}{\partial \mathrm{r}}\left(\mathrm{rk} \frac{\partial \mathrm{T}}{\partial \mathrm{r}}\right)+\frac{\partial}{\partial \mathrm{z}}\left(\mathrm{k} \frac{\partial \mathrm{T}}{\partial \mathrm{z}}\right)=0
$$

The boundary conditions are:

$$
\begin{gathered}
\mathrm{k} \frac{\partial \mathrm{T}}{\partial \mathrm{z}}(\mathrm{L}, \mathrm{r})=\mathrm{q}^{\prime \prime} \\
\mathrm{T}(0, \mathrm{r})=\mathrm{T}_{1} \\
\frac{\partial \mathrm{T}}{\partial \mathrm{r}}(\mathrm{z}, 0)=0 \\
\frac{\partial \mathrm{T}}{\partial \mathrm{r}}\left(\mathrm{z}, \mathbf{r}_{1}\right)=0
\end{gathered}
$$

The first two boundary conditions represent the boundary conditions applied to the two facesheets of the honeycomb core panel. The first boundary condition represents an applied constant heat flux, while the second boundary condition represents a constant temperature boundary condition. The last two boundary conditions represent symmetry conditions at 
the cell center and boundary. A schematic of the geometry considered for this simulation is shown in Figure 2. The finite volume formulation of the conservation of energy equation was developed by performing an energy balance at each node: ${ }^{11}$

$$
\begin{aligned}
& U_{i, j}\left(T_{i, j}-T_{i-1, j}\right)+V_{i, j}\left(T_{i, j}-T_{i+1, j}\right)+ \\
& W_{i, j}\left(T_{i, j}-T_{i, j-1}\right)+X_{i, j}\left(T_{i, j}-T_{i, j+1}\right)- \\
& E_{i, j}+G_{i, j}=0 \quad\left(i=1, n_{i} ; j=1, n_{j}\right)
\end{aligned}
$$

where $T_{i, j}$ was the nodal temperature, $U_{i . j}, V_{i, j}, W_{i, j}$, and $X_{i, j}$ were the thermal conductances, which in their most general form for non-uniform nodal spacing (nodes being at the centroids of the volume cells) and for nonhomogeneous material were given by:

$$
\begin{aligned}
& \mathrm{U}_{\mathrm{i}, \mathrm{j}}=\frac{\mathbf{k}_{\mathrm{i} . \mathrm{j}} \Delta \mathrm{r}_{\mathrm{i}}+\mathrm{k}_{\mathrm{i}-1, \mathrm{j}} \Delta \mathrm{r}_{\mathrm{i}-1}}{\Delta \mathrm{r}_{\mathrm{i}}+\Delta \mathrm{r}_{\mathrm{i}-1}} \frac{\left(\mathrm{r}_{\mathrm{i}}-0.5 \Delta \mathrm{r}_{\mathrm{i}}\right) \Delta z_{\mathrm{j}}}{\mathrm{r}_{\mathrm{i}}-\mathrm{r}_{\mathrm{i}-1}} \\
& \mathrm{~V}_{\mathrm{i}, \mathrm{j}}=\frac{\mathbf{k}_{\mathrm{i} . \mathrm{j}} \Delta \mathrm{r}_{\mathrm{i}}+\mathrm{k}_{\mathrm{i}+1, \mathrm{j}} \Delta \mathrm{r}_{\mathrm{i}+1}}{\Delta \mathrm{r}_{\mathrm{i}}+\Delta \mathrm{r}_{\mathrm{i}+1}} \frac{\left(\mathbf{r}_{\mathrm{i}}+0.5 \Delta \mathrm{r}_{\mathrm{i}}\right) \Delta z_{\mathrm{j}}}{\mathbf{r}_{\mathrm{i}+1}-\mathrm{r}_{\mathrm{i}}} \\
& \mathrm{W}_{\mathrm{i}, \mathrm{j}}=\frac{\mathrm{k}_{\mathrm{i} . \mathrm{j}} \Delta \mathrm{z}_{\mathrm{j}}+\mathrm{k}_{\mathrm{i}, \mathrm{j}-1} \Delta \mathrm{z}_{\mathrm{j}-1}}{\Delta \mathrm{z}_{\mathrm{j}}+\Delta \mathrm{z}_{\mathrm{j}-1}} \frac{\mathrm{r}_{\mathrm{i}} \Delta \mathrm{r}_{\mathrm{i}}}{\mathrm{z}_{\mathrm{j}}-\mathrm{z}_{\mathrm{j}-1}} \\
& X_{i, j}=\frac{k_{i . j} \Delta z_{j}+k_{i, j+1} \Delta z_{j+1}}{\Delta z_{j}+\Delta z_{j+1}} \frac{r_{i} \Delta r_{i}}{z_{j+1}-z_{j}}
\end{aligned}
$$

where $r_{i}$ and $z_{j}$ were the radial and axial nodal positions, and $\Delta r_{i}$ and $\Delta z_{j}$ were the dimensions of the control volume cells in the radial and axial directions, respectively. $n_{i}$ was the total number of cells in the radial direction, while $n_{j}$ was the total number of cells in the axial direction. The first ratio term on the right hand side of Eq. (6a) through (6d) used the rule of mixtures to find the effective local thermal conductivity between two adjacent cells composed of different materials, and reduced to the thermal conductivity of the material if two adjacent cells were made of the same material. The numerator of the second ratio term on the right hand side of Eq. (6a) through (6d) was the effective area of the finite volume cell face for conduction into the cell, while the denominator was the distance between two adjacent cell centroids. The equations were modified for the cells on the boundaries based on the corresponding boundary conditions. The term $E_{i, j}$ in Eq. (5) represented the external heating applied at one facesheet, therefore it was zero everywhere in the domain except at the boundary nodes at $\mathrm{z}=\mathrm{L}\left(\mathrm{i}=1, \mathrm{n}_{\mathrm{i}}, \mathrm{j}=\mathrm{n}_{\mathrm{j}}\right)$, and was obtained by multiplying the applied heat flux by the cross sectional area of the respective control volume cells. The term $\mathrm{G}_{\mathrm{i}, \mathrm{j}}$ in $\mathrm{Eq}$. (5) represented radiant heat in the honeycomb cell enclosure and was zero everywhere except for control volume cells with control surfaces that participated in radiation exchange in the enclosure. These consisted of the control surfaces on the honeycomb core and on the adhesive layers at the top and bottom of honeycomb cores. Therefore, the term $\mathrm{G}_{\mathrm{i}, \mathrm{j}}$ was calculated by multiplying the radiant heat flux, $\mathrm{q}_{\mathrm{r}}{ }^{\prime}$, by the corresponding control volume surface areas.

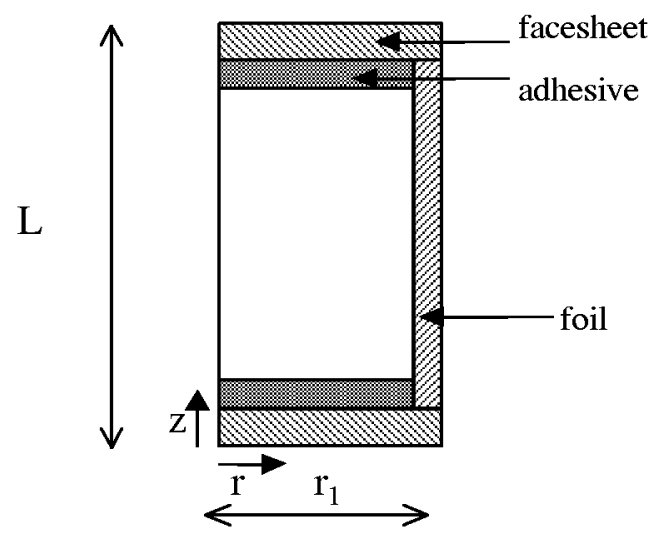

Figure 2. Schematic of honeycomb core geometry.

The radiant heat fluxes were calculated at each iteration by performing radiation exchange analysis in the enclosure assuming gray surfaces, with each control volume cell assumed to be isothermal with uniform surface radiosity, and furthermore, that both emitted and reflected radiation were diffuse. Letting $\theta_{\mathrm{k}}$ represent nodal temperature $T_{i, j}$ mapped to a single index, the incident radiant heat flux at each control volume surface in the honeycomb enclosure involved in radiation exchange was calculated from: ${ }^{12}$

$$
\mathrm{q}_{\mathrm{r}, \mathrm{i}}^{\prime \prime}=\sum_{\mathrm{k}=1}^{\mathrm{N}} \Lambda_{\mathrm{ik}} \sigma \theta_{\mathrm{k}}^{4}, \quad 1 \leq \mathrm{i} \leq \mathrm{N}
$$

where:

$$
\begin{gathered}
\Lambda_{\mathrm{ik}}=\frac{\varepsilon_{\mathrm{i}}}{1-\varepsilon_{\mathrm{i}}}\left(\delta_{\mathrm{ik}}-\Psi_{\mathrm{ik}}\right) \\
\Phi_{\mathrm{ik}}=\frac{\Psi_{\mathrm{ik}}=\Phi_{\mathrm{ik}}^{-1}-\left(1-\varepsilon_{\mathrm{i}}\right) \mathrm{F}_{\mathrm{A}_{\mathrm{i}-} \mathrm{A}_{\mathrm{k}}}}{\varepsilon_{\mathrm{i}}}
\end{gathered}
$$

where $\mathrm{N}$ was the total number of control volume surfaces involved in radiation exchange in the enclosure, $\varepsilon_{\mathrm{i}}$ was the surface emissivity for each control volume cell, $\delta_{\mathrm{ik}}$ was the Kronecker delta, and $\mathrm{F}_{\mathrm{Ai}-\mathrm{Ak}}$ was the shape factor for radiation exchange between surfaces designated as $A_{i}$ and $A_{k}$. The shape factors for the radiation exchange were calculated using the shape 
factor equations provided by Swann and Pittman ${ }^{1}$ for the same geometry.

The modified Newton-Raphson method was used to solve the nonlinear set of equations: ${ }^{13}$

$$
\begin{gathered}
{[\mathbf{J}]^{\mathbf{m}}\{\boldsymbol{\Delta} \boldsymbol{\theta}\}^{\mathbf{m + 1}}=-\{\mathbf{F}\}^{m}} \\
\{\boldsymbol{\theta}\}^{m+1}=\{\boldsymbol{\theta}\}^{m}+\{\boldsymbol{\Delta} \boldsymbol{\theta}\}^{m+1}
\end{gathered}
$$

where the superscript $m$ denotes the $m^{\text {th }}$ iteration, $[\mathrm{J}]^{\mathrm{m}}$ was the Jacobian matrix, $\{\Delta \theta\}^{\mathrm{m}+1}$ was the nodal temperature increments vector caused by the residual load vector $\{\mathrm{F}\}^{\mathrm{m}}$. The Jacobian matrix was defined as:

$$
\mathbf{J}_{i, j}=\frac{\partial F_{i}}{\partial \theta_{j}}
$$

The Jacobian matrix was calculated by finite-difference numerical differentiation at the first iteration and was held constant. Once the numerical solution had converged, the effective thermal conductivity was calculated based on the applied heat flux boundary condition and the converged average temperature difference between the two facesheets and the sample overall thickness using the Fourier's law of heat conduction. $^{14}$

Published results were used for the thermal conductivity of the titanium honeycomb core (Ti-3Al$2.5 \mathrm{~V}),{ }^{15}$ and air. ${ }^{14}$ No data were found for the facesheets material, Ti-6-22-22. Therefore thermal properties for Ti-6Al-4V were used for the facesheets. ${ }^{16}$ The thermal conductivity of the adhesive layer was unknown. It was decided to investigate two values for the thermal conductivity of the adhesive that would provide an upper and lower range for this property. It was assumed that the ratio of the thermal conductivity of the adhesive to the thermal conductivity of air over the temperature range of interest was either 10 or 100 . This would result in thermal conductivity of the adhesive ranging between 0.251 and $2.51 \mathrm{~W} / \mathrm{mK}$ at room temperature. This would cover the range of thermal conductivity values for typical adhesives and epoxies. The emissivity of titanium foil and adhesive layer were assumed to be independent of temperature in the temperature range of interest and equal to $0.3^{17}$ and 0.8 , respectively. The emissivity of nonmetallic solids generally varies between 0.7 and $0.9,{ }^{12}$ therefore, an emissivity of 0.8 was assumed for the adhesive layer.

\section{Modified Swann and Pittman Model}

It was further decided to investigate a modification to the original Swan and Pittman semi-empirical relationship. The proposed modification incorporated the facesheets and the adhesive in the thermal model. The equivalent thermal network model consisted of five thermal resistances in series arrangement. Two of the resistances were for the solid conduction through the facesheets. Two other resistances were the effective resistances for the parallel arrangement of solid conduction through the adhesive and the segment of honeycomb foil covered by the adhesive. The last resistance was the effective resistance for the parallel arrangement of conduction through the gas (air) and remaining honeycomb foil along with the superimposed radiation conduction term. Thus, the effective thermal conductivity for this thermal network was obtained from the following relationship:

$$
\begin{aligned}
\frac{\mathrm{L}}{\mathrm{k}_{\mathrm{e}}} & =2 \frac{\mathrm{L}_{\mathrm{fs}}}{\mathrm{k}_{\mathrm{fs}}}+2 \frac{\mathrm{L}_{\mathrm{ad}}}{\mathrm{k}_{\mathrm{f}} \frac{\Delta \mathrm{A}}{\mathrm{A}}+\mathrm{k}_{\mathrm{ad}}\left(1-\frac{\Delta \mathrm{A}}{\mathrm{A}}\right)} \\
& +\frac{\mathrm{L}^{\prime}}{\mathrm{k}_{\mathrm{f}} \frac{\Delta \mathrm{A}}{\mathrm{A}}+\mathrm{k}_{\mathrm{g}}\left(1-\frac{\Delta \mathrm{A}}{\mathrm{A}}\right)+\mathrm{k}_{\mathrm{r}}}
\end{aligned}
$$

where $\mathrm{L}_{\mathrm{fs}}, \mathrm{L}_{\mathrm{ad}}$, and $\mathrm{L}$ were the thicknesses of the facesheet, adhesive, and the honeycomb core panel, respectively, $L^{\prime}$ was the thickness of the gas column in the honeycomb core ( $\left.\mathrm{L}^{\prime}=\mathrm{L}-2 \mathrm{~L}_{\mathrm{fs}}-2 \mathrm{~L}_{\mathrm{ad}}\right)$, and $\mathrm{k}_{\mathrm{fs}}, \mathrm{k}_{\mathrm{f}}, \mathrm{k}_{\mathrm{ad}}$, and $\mathrm{k}_{\mathrm{g}}$ were the thermal conductivities of the facesheet, foil, adhesive and gas, correspondingly. Note that $\mathrm{k}_{\mathrm{r}}$ was the radiant thermal conductivity calculated from Eq. (2). The original Swann and Pittman model was developed assuming that the facesheets and foils had the same emissivity. The adhesive layers at the top and bottom of the honeycomb cell had a different emissivity value than the honeycomb core foil. In order to utilize the Swann and Pittman radiation model, a weighted emittance based on the ratio of the surface area of each material to the total surface area involved in the radiation exchange in the enclosure was calculated. This yielded a weighted emissivity of 0.382 .

\section{$\underline{\text { Results and Discussion }}$}

Before proceeding to presentation of the finite volume numerical results for the adhesively bonded geometry, the finite volume numerical model was applied to the honeycomb core panel geometry without any adhesive layers in order to assess the accuracy of the numerical results by comparison with the Swann and Pittman predictions using Eq. (1). It was assumed 
in the numerical model that the emittance of the facesheets was equal to the emittance of the honeycomb foils, 0.3. The effective thermal conductivities of the honeycomb core panel without the adhesive layers at various temperatures were calculated using the converged finite volume numerical solution of the combined conduction and radiation heat transfer. The results and the Swann and Pittman predictions are shown in Figure 3, where the effective thermal conductivities are plotted versus average honeycomb panel temperatures. The Swann and Pittman model overpredicted the numerical results below $300 \mathrm{~K}$ and underpredicted the numerical results above $300 \mathrm{~K}$, with the difference increasing with increasing temperature. The average difference between the Swann and Pittman model and the finite volume numerical predictions was $-3.5 \pm 6.6$ percent. Considering that the Swann and Pittman model ignores the facesheets and provides a semi-empirical relationship for modeling the radiation heat transfer, this close agreement between the finite volume numerical predictions and the semi-empirical results validated the numerical method. These results were also in general agreement with results from Stroud $^{2}$ who had showed a root mean square deviation of $7 \%$ between his experimental values and predictions using the Swann and Pittman semi-empirical relationship over a temperature range of 670 to $1050 \mathrm{~K}$.

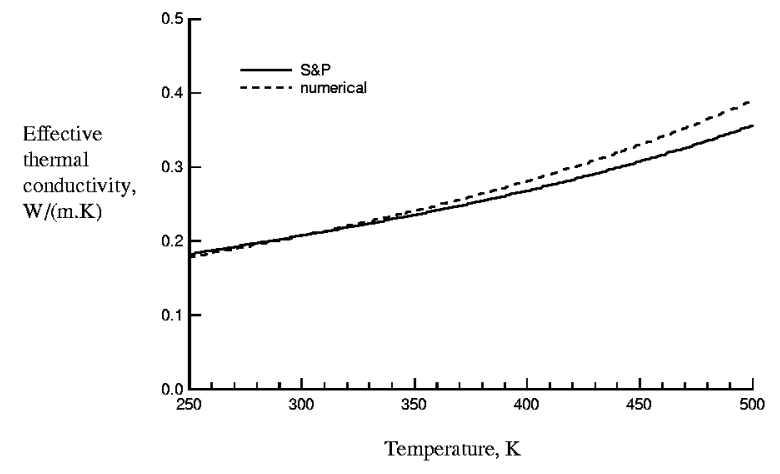

Figure 3. Comparison of finite volume numerical model and Swann and Pittman model ${ }^{1}$ for honeycomb core panel without adhesive.

The effective thermal conductivities of the honeycomb core panel with the adhesive layers at various temperatures were calculated using the converged finite volume numerical solution of the combined conduction and radiation heat transfer. As discussed previously, results were obtained with the ratio of the thermal conductivity of adhesive to air of 10 and 100 . The variation of effective thermal conductivity with temperature calculated from the numerical results at the two adhesive thermal conductivity values is presented in Figure 4. The experimental data and the Swann and Pittman predictions are also shown in the figure. The average percent differences for the effective thermal conductivity of the Swann and Pittman model and the four experimental sets of data with respect to the average numerical predictions are presented in Table 2 . The average numerical prediction was obtained by averaging the data obtained at the two different values of adhesive thermal conductivity. It is evident that the radiant step heating data had provided the best agreement with the numerical predictions, with the data clearly falling in between the two curves corresponding to the two thermal conductivity values of the adhesive. Using the average numerical predictions as the basis for reference, the percent difference for the radiant step heating measurements was $1.7 \pm 5.9$; the percent difference for the heat flow meter measurements was $12.9 \pm 26.8$; while the two sets of guarded hot plate data produced differences larger than 38 percent. These results do not in any way question the validity of the steady state techniques, but imply that the measurements obtained for the samples were inaccurate.

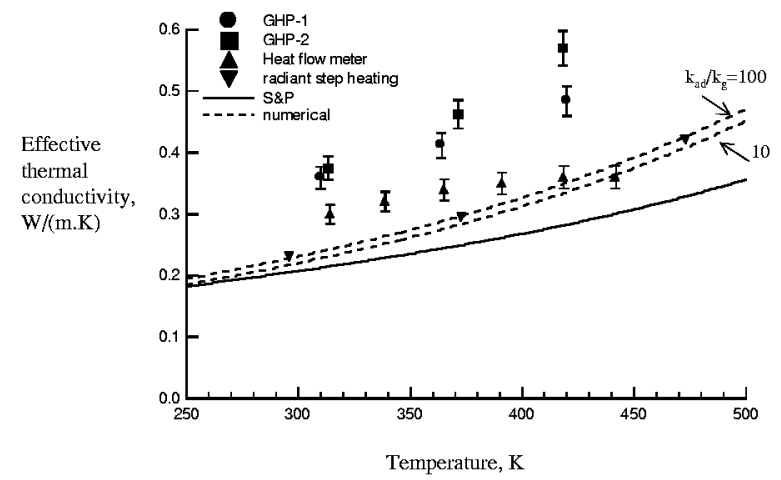

Figure 4. Comparison of effective thermal conductivity predicted using the numerical model with previous measurements and the Swann and Pittman model ${ }^{1}$ for thermal conductivity of adhesive to air ratios of 10 and 100 . 


\begin{tabular}{|l|c|}
\hline $\begin{array}{l}\text { measurement } \\
\text { technique or } \\
\text { prediction method }\end{array}$ & $\begin{array}{c}\text { average percent } \\
\text { error }\end{array}$ \\
\hline Guarded Hot Plate-1 & $38.0 \pm 18.1$ \\
\hline GHP-2 & $47.3 \pm 11.1$ \\
\hline heat flow meter & $12.9 \pm 26.8$ \\
\hline radiant step heating & $1.7 \pm 5.9$ \\
\hline Swann \& Pittman & $-15.2 \pm 12.6$ \\
\hline
\end{tabular}

Table 2. Average percent differnce of various experimental data and Swann and Pittman model ${ }^{1}$ with respect to average predictions by the finite volume numerical model.

The percent difference between the average numerical results and the Swann and Pittman model was $-15.2 \pm 12.6$. It is obvious that the Swann and Pittman semi-empirical relationship is insufficient for modeling the heat transfer in the adhesively bonded honeycomb panel used in this investigation. It can be concluded that the adhesive layer has a significant effect on the overall thermal performance of honeycomb core panels and should not be ignored in the calculations. In a honeycomb core panel at moderate temperatures where radiation is not a significant mode of heat transfer, most of the heat transfer takes place through the honeycomb core foils. In the absence of the adhesive layers, heat is conducted from the facesheets to the foil through the small cross sectional areas of the foil, $\pi \mathrm{Dt}_{\mathrm{f}}$, where $\mathrm{t}_{\mathrm{f}}$ is foil thickness and $\mathrm{D}$ the hydraulic diameter. In the presence of adhesive layers heat is also transferred from the facesheets to the adhesive layer and then from the adhesive layer to the foil through an area equal to $\pi \mathrm{DL}_{\mathrm{ad}}$, where $\mathrm{L}_{\mathrm{ad}}$ is the adhesive thickness. Depending on the thermal conductivity and thickness of the adhesive layer, this added path for conduction of heat from the facesheet to foil through the adhesive, could result in higher heat conduction rates through the overall honeycomb core panel.

For the honeycomb core panel geometry of the present study, the finite volume numerical results and the modified Swann and Pittman results for the thermal conductivity of adhesive to air ratio of 10 are shown in Figure 5. The Swann and Pittman predictions are also included in the figure. The modified Swann and Pittman overpredicted the numerical results below 400 $\mathrm{K}$ and underpredicted the numerical results above this temperature, but it is consistently higher compared to the original Swann and Pittman. The percent difference between the modified model and numerical results was $3.2 \pm 12.5$. The percent difference between the modified model and finite volume numerical results for thermal conductivity of adhesive to air ratio of 100 was $2.3 \pm 11.6$. These percent differences were significantly lower compared to the Swann and Pittman model and to all the steady state experimental results. It can be concluded that the modified Swann and Pittman model is a good first-order approximation for predicting the effective thermal conductivity of adhesively bonded honeycomb core panels.

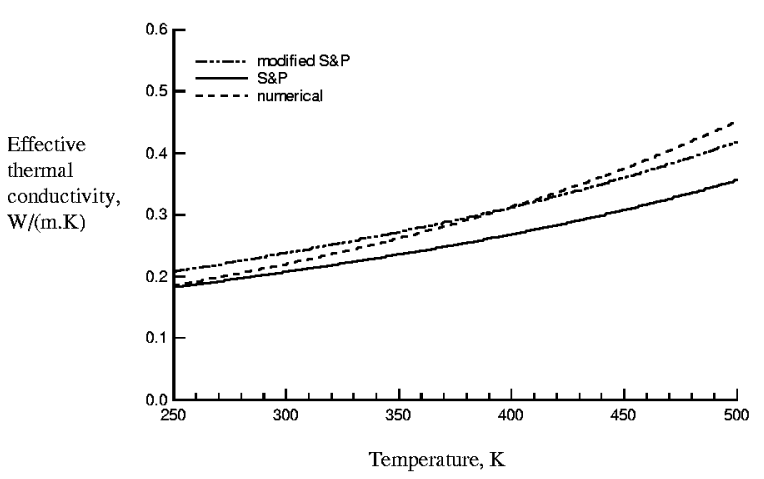

Figure 5. Comparison of effective thermal conductivity predicted using the modified Swann and Pittman model with numerical model and the Swann and Pittman model for thermal conductivity of adhesive to air ratios of 10 .

The finite volume numerical model was used to parametrically study the effects of adhesive thickness and thermal conductivity on the effective thermal conductivity at a mean temperature of $300 \mathrm{~K}$. The ratio of the adhesive layer thickness (on each side) to honeycomb foil height was varied between zero and 0.05 , with zero representing a construction with no adhesive. The geometry studied in this investigation had an adhesive thickness to foil height ratio of 0.037 . Data were obtained for the ratio of thermal conductivity of adhesive to air being equal to $1,5,10,25,50$, and 100. All the other parameters were kept fixed at the values corresponding to the geometry studied in this investigation. Results presented in Figure 6 illustrate the variation in effective thermal conductivity increase due to the adhesive with the ratio of the adhesive layer thickness to honeycomb foil height for various values of the ratio of the adhesive to air thermal conductivity. All the data converged to zero percentage increase when the adhesive thickness was zero. The effective thermal conductivity increased with increasing adhesive thickness and adhesive thermal conductivity. 


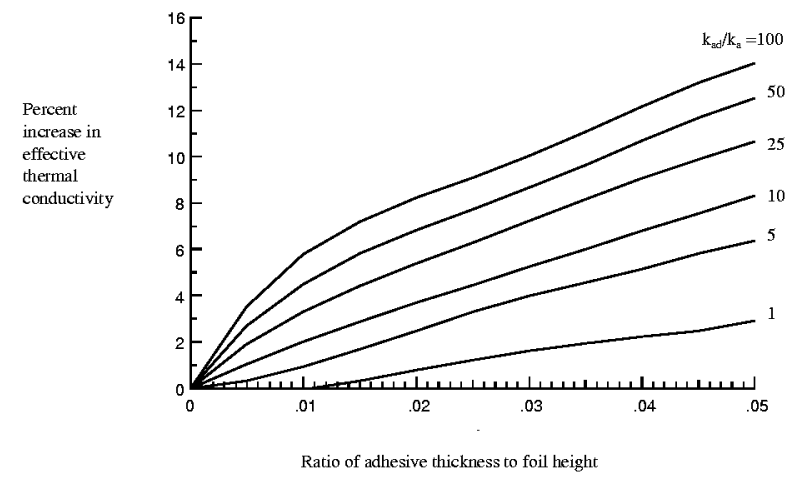

Figure 6. Percent increase in effective thermal conductivity as a function of ratio of adhesive thickness to foil height for thermal conductivity of adhesive to air ratios of $1,5,10,25,50$, and 100 .

The data for adhesive to air thermal conductivity ratio of unity illustrated the influence of adhesive emissivity and thickness on the radiation heat transfer. The adhesive did not change the conduction heat transfer through the geometry since it had the same thermal conductivity as air, and thus the effect of the adhesive on the radiation heat transfer could be isolated. The adhesive had a higher emissivity than the facesheets, and the adhesive thickness changed the overall height of the enclosure for radiation exchange. The effective conductivity increased with increasing adhesive thickness and resulted in a maximum three percent higher effective thermal conductivity at the adhesive thickness to foil height ratio of 0.05 .

The data for adhesive thermal conductivities larger than that of air exhibited a larger increase in the effective thermal conductivity with increasing adhesive thickness and with increasing adhesive thermal conductivity. The higher increases were due to the combination of increases in the radiation heat transfer and solid conduction heat transfer. As discussed previously, the adhesive layer provided a larger surface area with higher thermal conductivity to conduct heat from the facesheets to the foils than did the foil edge. The difference between the data for adhesive thermal conductivity ratios greater than one compared to ratios equal to one provided a rough estimate of the magnitude of the higher heat transfer due to conduction within the adhesive. At an adhesive to air thermal conductivity ratio of 100 , the adhesive's thermal conductivity approached that of the titanium facesheets, and the problem reduced to heat transfer in a honeycomb structure with an effectively thicker facesheet and smaller foil height. The data in the figure provide an estimate of the errors encountered when neglecting the influence of the adhesive in the overall heat transfer.

\section{Concluding Remarks}

The effective thermal conductivity of an adhesively bonded honeycomb core structure had been measured using three different techniques at four thermophysical property measurement laboratories over the temperature range of $300-500 \mathrm{~K}$. Two laboratories had utilized the guarded hot plate technique, one laboratory had used the heat flow meter apparatus based on ASTM Standard C518, which is a steady-state comparative technique, and one laboratory had used the transient radiant step heating technique. The four sets measurements varied significantly from each other and from the semiempirical Swann and Pittman model. ${ }^{1}$

The combined steady-state radiation and conduction heat transfer in the honeycomb core panel was modeled using a finite volume numerical formulation. The nonlinear governing equations were solved using a modified Newton-Raphson method. The effective thermal conductivities were calculated from the converged steady-state solutions of the numerical finite volume model using thermal conductivity of adhesive to air ratios of 10 and 100 . The transient radiant step heating experimental data were found to be in best agreement with the numerical finite volume predictions with a percent difference of 1.7 \pm 5.9 .

A modification of the Swann and Pittman semiempirical relationship which incorporated the facesheets and adhesive layers in the thermal model provided satisfactory agreement with the finite volume numerical results. The percent difference between the numerical predictions and the modified model for thermal conductivity of adhesive to air ratios of 10 and 100 were $3.2 \pm 12.5$ and $2.3 \pm 11.6$, respectively. It can be concluded that the modified Swann and Pittman model is a good first-order approximation for predicting the effective thermal conductivity of adhesively bonded honeycomb core panels. A parametric study was conducted to determine the effects of adhesive thickness and thermal conductivity on the effective thermal conductivity. It was determined that the effective thermal conductivity of the panel increases with increasing adhesive thickness and adhesive thermal conductivity. 


\section{$\underline{\text { References }}$}

1. Swann, R.T., and Pittman, C.M., "Analysis of Effective Thermal Conductivities of HoneycombCore and Corrugated-Core Sandwich Panels," NASA Technical Note D-714, April 1961.

2. Stroud, C.W., " Experimental Verification of an Analytical Determination of Overall Thermal Conductivity of Honeycomb-Core Panels" NASA Technical Note D-2866, June 1965.

3. Eftekhar, J., Darkazalli, G., and Haji-Sheikh, A., "Conduction of Heat across Rectangular Cellular Enclosures," Journal of Heat Transfer, Vol. 103, August 1981, pp. 591-595.

4. Fairbanks, D. R., "Effective Lateral Thermal Conductivity of Square Cell Enclosures," AIAA Journal, Vol. 20, No. 7, July 1982, pp. 1009-1014.

5. Jones, P.D., "Combined Radiation and Conduction Heat Transfer Through Evacuated HoneycombCored Panels," ASME HTD-Vol. 299, Heat Transfer with Combined Modes, 1994, pp. 23-30.

6. Copenhaver, D.C., Scott, E.P., and Hanuska, A., "Thermal Characterization of Honeycomb Core Sandwich Structures," AIAA Paper 97-2455, AIAA $32^{\text {nd }}$ Thermophysics Conference, June 2325, 1997, Atlanta, GA.

7. Edwards, D.K, Arnold, J.N. and Wu, P.S., "Correlations for Natural Convection through High L/D rectangular cells," Journal of Heat Transfer, Vol. 101, November 1979, pp. 741-743.

8. ASTM Standard C 177, "Standard Test Method for Steady-State Heat Flux Measurements and Thermal Transmission Properties by Means of the GuardedHot-Plate Apparatus," 1996 Annual Book of ASTM Standards, Vol. 4.06, Thermal Insulation, Environmental Acoustics, 1996.

9. ASTM Standard C 518, "Standard Test Method for Steady-State Thermal Transmission Properties by Means of the Heat Flow Meter Apparatus," 1996 Annual Book of ASTM Standards, Vol. 4.06, Thermal Insulation, Environmental Acoustics, 1996.

10. Coleman, H.W. and Steele, W.G., Experimentation and Uncertainty Analysis for Engineers, 1989, John Wiley \&Sons, Inc.
11. Razelo, P., "Methods of Obtaining Approximate Solutions," Chapter 4, Handbook of Heat Transfer, edited by W.M. Rohsenow and J.P. Hartnet, 1973, McGraw-Hill.

12. Sparrow, E.M. and Cess, R.D., Radiation Heat Transfer, Augmented Edition, 1978, McGraw-Hill.

13. Huebner, K.H. and Thornton, E.A., The Finite Element Method for Engineers, $2^{\text {nd }}$ ed., 1982, John Wiley \& Sons.

14. Kreith, F., and Black, W.Z., Basic Heat Transfer, 1980, Harper \& Row Publishers.

15. Aerospace Structural Metals Handbook, 1994, edited by Brown, W.F., Jr., Published by CINDAS/USAF CRDA Handbooks Operations, Purdue University.

16. Williams, S.D., and Curry, D.M., "Thermal Protection Materials- Thermophysical Property Data," NASA RP-1289, December 1992.

17. Touloukian, Y.S., and DeWitt, D.P., Thermal Radiation Properties: Metallic Elements and Alloys, vol. 7 of Thermophysical Properties of Matter Series, IFI/Plenum, 1970. 